Artículo científico

Volumen 31(1): 177-192. Enero-abril, 2020

e-ISSN 2215-3608, doi:10.15517/am.v31i1.36596

http://www.revistas.ucr.ac.cr/index.php/agromeso

\title{
Características productivas de cultivos forrajeros en sistemas de producción de leche, Nariño, Colombia ${ }^{1}$
}

\section{Productive characteristics of forage crops for supplementation in milk production systems, Nariño, Colombia}

\author{
David Felipe Nieto-Sierra ${ }^{2}$, Diego Hernán Meneses-Buitrago², Sonia Patricia Morales-Montero², Filadelfo \\ Hernández-Oviedo², Edwin Castro-Rincón ${ }^{2}$
}

1 Recepción: 24 de abril, 2019. Aceptación: 9 de octubre, 2019. Este trabajo formó parte del proyecto de tesis de Maestría del primer autor, llevado a cabo en el marco del proyecto denominado "Mejoramiento de la oferta forrajera, optimización de los sistema de alimentación y aseguramiento de la calidad e inocuidad de la leche en el trópico alto del departamento de Nariño", financiado por el Sistema General de Regalías y Gobernación de Nariño, ejecutado por el Centro de Investigación Obonuco de la Corporación Colombiana de Investigación Agropecuaria (AGROSAVIA), Pasto, Nariño.

2 Corporación Colombiana de Investigación Agropecuaria (AGROSAVIA). Centro de Investigación Obonuco. Km 5, Vía Pasto, Obonuco, Nariño, Colombia.dnieto@agrosavia.co,dmeneses@agrosavia.co (https://orcid.org/0000-0003-3033-3079), spmorales@agrosavia.co, fhernandez@agrosavia.co, ecastro@agrosavia.co (https://orcid.org/0000-0001-9841-8242).

\section{Resumen}

Introducción. El pasto es la fuente principal de alimentación de los rumiantes, sin embargo, este no es capaz de aportar los nutrientes necesarios requeridos para su mantenimiento y productividad, sumado a esto, en el trópico alto es muy notable la estacionalidad de producción de forrajes, por lo que es muy importante conocer otras alternativas de alimentación. Objetivo. Caracterizar y evaluar diez cultivos forrajeros como fuentes alternativas de suplementación en sistemas de producción de leche en el trópico alto de Nariño. Materiales y métodos. El estudio se realizó en tres localidades (L1, L2 Y L3) representativas de la cuenca lechera del departamento de Nariño entre noviembre de 2016 y setiembre de 2017. Se empleó un diseño de bloques completos al azar (BCA) con diez tratamientos Vicia faba (alpargata), Vicia faba (roja), Vicia faba (común), Zea mayz var. ICA V-305, Raphanus sativus L., Beta vulgaris, Avena sativa var. Cayuse, Phalaris sp., Medicago sativa L. var. moapa, Medicago sativa L. var. 10 10, tres repeticiones y comparación de medias al 0,05. Al momento de la cosecha se estimó: rendimiento de forraje verde y materia seca, proteína cruda (PC), fibra detergente neutro (FDN), fibra detergente ácido (FDA), lignina, hemicelulosa, digestibilidad de la materia seca y energía neta de lactancia (ENL). Resultados. Las especies destacadas fueron la haba (las tres variedades) y la remolacha forrajera, por su rendimiento y calidad nutricional, las cuales presentaron valores entre 7,48 y $20,24 \%$ para PC y 1,14 y 1,49 Mcal kg-1 para ENL. Se presentaron diferencias entre tratamientos para cada localidad, tanto en las variables productivas como en las nutricionales. Conclusión. Las especies forrajeras de mayor rendimiento productivo y calidad nutricional fueron la haba (roja, común y alpargata) y la remolacha.

Palabras claves: forraje verde, materia seca, espectroscopia infrarroja, calidad nutricional.
Abstract
Introduction. Grass is the main source of feed for ruminants, however, it is not able to provide the nutrients required for its maintenance and productivity, added to this, in the high tropics is very noticeable the seasonality of 
fodder production, so it is very important to know other feeding alternatives. Objective. Characterize and evaluate ten forage crops as alternative sources of supplementation in milk production systems in the high tropic of Nariño. Materials and methods. The study was carried out in three localities (L1, L2 and L3) representative of the milk basin of the department of Nariño between november 2016 and september 2017. A Random Complete Blocks (BCA) design was used with ten treatments Vicia faba (espadrille), Vicia faba (red), Vicia faba (common), Zea mayz var. ICA V-305, Raphanus sativus L., Beta vulgaris, Avena sativa var. Cayuse, Phalaris sp., Medicago sativa L. var. moapa, Medicago sativa L. var. 1010 , three repetitions and comparison of averages to 0.05 . A the time of harvest it was estimated: green forage yield and dry matter, crude protein (PC), neutral detergent fibre (FDN)), acid detergent fibre (FDA), lignin, hemicellulose, dry matter digestibility, and net lactation energy (ENL). Results. The outstanding species were the bean (the three varieties) and fodder beet for its yield and nutritional quality, which presented values between 7.48 and 20.24 $\%$ for PC and 1.14 and $1.49 \mathrm{Mcal} \mathrm{kg}^{-1}$ for ENL. Differences between treatments were presented for each locality, both in productive and nutritional variables. Conclusion. The forage species with the highest productive yield and nutritional quality were the three bean varieties (red, common, and espadrille) and beet.

Keywords: green forage, dry matter, infrared spectroscopy, nutritional quality.

\section{Introducción}

Los bovinos son muy versátiles respecto a la alimentación, sin embargo el pasto es y será la base fundamental de su alimentación (Trujillo, 2009; Mora et al., 2014), aunque por sí solo es incapaz de aportar todos los nutrientes necesarios para su mantenimiento y productividad sostenida de los vacunos, de ahí la importancia de conocer las diversas fuentes de nutrientes y su correcta utilización (Trujillo, 2009).

En el trópico alto es muy notable la producción estacional de forrajes; se obtienen pastos abundantes en épocas de lluvia y con poco crecimiento en épocas de verano, con una distribución de un 70 y un $30 \%$ de la producción forrajera, respectivamente (Betancourt et al., 2012; Anzola et al., 2014). Además, hay un efecto determinante del clima sobre la producción y la calidad del forraje que influyen directamente sobre la productividad de los animales (Mora et al., 2014).

Se debe considerar también, que la mayoría de las pasturas son de reducida calidad nutritiva, debido principalmente al manejo deficiente de las praderas, en relación con los tiempos de uso y descanso, renovación de praderas, o bien, al establecimiento de pastizales con especies mejoradas (Anzola et al., 2014).

La producción de leche en Colombia está basada en un $85 \%$ en pasturas de kikuyo (Cenchrus clandestinus), en algunos casos se presenta en mezclas con leguminosas y con otras gramíneas como raygrass (Lolium sp.) (Echeverry et al., 2010; Morales et al., 2013; Carulla y Ortega, 2016). El kikuyo es una especie tropical que se ha naturalizado en el país, es de buena adaptación y se ha vuelto endémico en microrregiones de altiplanicies y laderas frías (Morales et al., 2013). Es una planta C4, lo que confiere una mayor adaptación a condiciones de déficit hídrico (Lira, 2007), pero en la actualidad se registra baja productividad por deficiencias en las prácticas de manejo y por susceptibilidad a heladas; por estas razones, es benéfico establecer praderas con mezclas de pastos que permita ofrecer una mayor diversidad de alimento para el ganado y contrarrestre estas limitantes (Navia et al., 2015); los cuales provocan que los productores acudan permanentemente al uso de concentrados y granos, que incrementan los costos de producción. Una manera de enfrentar estos problemas es la alimentación estratégica con el adecuado uso de los recursos alimenticios disponibles (Mora et al., 2014). Por esta razón, las ganaderías productoras de leche exploran diversas alternativas forrajeras, tanto en el rubro de las praderas como de los cultivos forrajeros y especies arbóreas endémicas, en forma de ensilaje o heno en aras de mejorar la rentabilidad y sostenibilidad del sistema de producción (Chilibroste, 2012; Mejía et al., 2013). 
Los cultivos forrajeros seleccionados en este estudio fueron especies que crecen bien en altitudes de $2200 \mathrm{msnm}$ en adelante, a una temperatura entre 15 y $22{ }^{\circ} \mathrm{C}$, donde predominan sistemas de lechería (Guerrero, 1998; Molano et al., 2011); algunas leguminosas, porque se reconocen como fuente de excelente forraje y como mejoradoras de la fertilidad del suelo, y otras especies de corto y mediano plazo de alto rendimiento, que permiten obtener un forraje abundante durante ciertas épocas del año; estos pastos se pueden suministrar directo a los animales o mediante prácticas de ensilaje, henificación o henolaje (Guerrero, 1998).

El objetivo de este trabajo fue caracterizar y evaluar diez cultivos forrajeros como fuentes alternativas de suplementación en sistemas de producción de leche en el trópico alto de Nariño.

\section{Materiales y métodos}

\section{Localización}

El estudio para caracterizar y evaluar diez cultivos forrajeros se llevó a cabo entre noviembre 2016 y setiembre 2017, en tres localidades del departamento de Nariño, Colombia. Las localidades 1 y 2 (L1 y L2) se ubican en el Centro de Investigación Obonuco de la Corporación Colombiana de Investigación Agropecuaria (AGROSAVIA), municipio de Pasto, con alturas de $2905 \mathrm{msnm}$ y $2785 \mathrm{msnm}$, respectivamente, con una temperatura y precipitación promedio anual en las dos localidades de $12{ }^{\circ} \mathrm{C}$ y $1100 \mathrm{~mm}$, clasificadas como bosque seco montano bajo (Holdridge, 1982) datos obtenidos de la estación ganadera, de AGROSAVIA entre el año 2016 y 2017. La localidad 3 (L3) se ubica en la granja experimental Chimangual de la Universidad de Nariño, municipio de Sapuyes, con una altura de $3157 \mathrm{msnm}$, temperatura promedio de $9{ }^{\circ} \mathrm{C}$ y precipitación promedio anual de $1200 \mathrm{~mm}$ (Cuadro 1), se clasifica como una zona de bosque húmedo montano (UDENAR, 2016).

Cuadro 1. Ubicación y parámetros edafoclimáticos de las localidades donde se establecieron los experimentos para caracterizar y evaluar diez cultivos forrajeros. Nariño, Colombia. 2016-2017.

Table 1. Location and edaphoclimatic parameters of the localities where the experiments were established, to characterize and evaluate ten forage crops. Nariño, Colombia. 2016-2017.

\begin{tabular}{|c|c|c|c|c|c|c|}
\hline Municipio & Localidades & Coordenadas & $\begin{array}{l}\text { Altitud } \\
\text { (msnm) }\end{array}$ & $\begin{array}{c}\text { Temperatura } \\
\text { media anual } \\
\left({ }^{\circ} \mathbf{C}\right)^{1} \\
\end{array}$ & $\begin{array}{c}\text { Precipitación } \\
\text { media anual } \\
(\mathrm{mm})^{1}\end{array}$ & $\begin{array}{l}\text { Textura de } \\
\text { suelo }\end{array}$ \\
\hline Pasto & $\begin{array}{l}\text { C.I. Obonuco } \\
\text { AGROSAVIA* }\end{array}$ & $\begin{array}{l}\text { N } 01^{\circ} 11^{\prime} 4,13^{\prime \prime} \\
\text { W } 77^{\circ} 19^{\prime} 0,19^{\prime \prime}\end{array}$ & $\begin{array}{l}2905 \\
2785\end{array}$ & 12 & 1100 & $\begin{array}{c}\text { Franco } \\
\text { arenosos }\end{array}$ \\
\hline Sapuyes & $\begin{array}{l}\text { Granja Exp. Chimangual } \\
\text { Universidad de Nariño }\end{array}$ & $\begin{array}{l}\text { N } 01^{\circ} 02^{\prime} 6,55^{\prime \prime} \\
\text { W } 77^{\circ} 45^{\prime} 3,88^{\prime \prime}\end{array}$ & 3157 & 9 & 1200 & $\begin{array}{l}\text { Franco areno- } \\
\text { gravilloso }\end{array}$ \\
\hline
\end{tabular}

${ }^{1}$ Fuente/Source: Climate-Data.org, 2018.

* Centro de Investigación Obonuco, Corporación Colombiana de Investigación Agropecuaria / * Obonuco Research Center, Corporacion Colombiana de Investigacion Agropecuaria.

\section{Diseño experimental y análisis estadístico}

En las tres localidades se realizó la evaluación de rendimiento productivo y calidad nutricional de diez cultivos forrajeros (tratamientos) de uso local, mismos que se distribuyeron de la siguiente manera: T1: Zea mays L. var. ICA V 305, T2 Avena sativa L. var. var. Cayuse, T3: Beta vulgaris L., T4: Raphanus sativus L., T5: Phalaris sp., 
T6: Vicia faba L. (haba roja), T7: Vicia faba L. (haba común), T8: Vicia faba L. (haba alpargata), T9: Medicago sativa L. var. moapa y T10: Medicago sativa L. var. 10-10. En cada localidad se estableció un diseño experimental de bloques completos al azar con tres bloques y tres repeticiones por tratamiento, para un total de treinta parcelas. La parcela experimental fue de $30 \mathrm{~m}^{2}$, con una distancia de $1 \mathrm{~m}$ entre parcelas y $2 \mathrm{~m}$ entre bloques.

La información obtenida se analizó dependiendo de su varianza y distribución normal, para lo cual se realizó un análisis de varianza (ANOVA) acompañado de la prueba de comparación de medias de Tukey $(\alpha=0,05)$, así establecer diferencias significativas entre tratamientos dentro de cada localidad; para los análisis se utilizó el programa estadístico SAS V 9.4.

\section{Manejo agronómico de los cultivos}

La siembra de todos los tratamientos se realizó en el mes de noviembre de 2016 (80 mm). Los cultivos de avena, alfalfa y rábano forrajero se sembraron con semilla sexual y al voleo; mientras que el maíz, la remolacha forrajera y la haba se sembraron con semilla sexual, y con distancias que variaron entre surcos de $0,7 \mathrm{~m}$ y $0,9 \mathrm{~m}$ y entre plantas de $0,2 \mathrm{~m}$ a $0,5 \mathrm{~m}$. El pasto brasilero se sembró con semilla asexual (macollas) con distancias entre surcos $0,5 \mathrm{~m}$ y entre plantas $0,5 \mathrm{~m}$. Durante el establecimiento y desarrollo de los cultivos, se realizó el manejo agronómico (fertilización, control de arvenses, manejo de plagas y patógenos) acorde a recomendaciones técnicas de cada cultivo. La cosecha se realizó de acuerdo con la etapa fenológica óptima para cada cultivo (Cuadro 2).

\section{Variables de estudio}

$\mathrm{Al}$ término del ciclo productivo de cada especie, se evaluaron variables productivas y nutricionales. Para las variables productivas se determinó el rendimiento de forraje verde $(\mathrm{FV})$ y materia seca $(\mathrm{MS})$ por hectárea $\left(\mathrm{t} \mathrm{ha}^{-1}\right)$, a través de aforos realizados con un marco de $1 \mathrm{~m}^{2}$ (Salinas, 1982). Posteriormente, se obtuvó una muestra para determinar las siguientes variables nutricionales: proteína cruda (PC), fibra en detergente neutro (FDN), fibra en detergente ácido (FDA), lignina (LIG), hemicelulosa (HEM), digestibilidad de la materia seca (DIG) y energía neta de lactancia (ENL), de acuerdo con los procedimientos utilizados en la metodología NIRS (Ariza-Nieto et al., 2017), con el equipo (NIRS DS 2500 - FOSS Analytrical A/S - Dinamarca).

\section{Resultados}

Durante el año de evaluación se presentaron dos épocas definidas, una de altas precipitaciones y otra de bajas. La distribución de estas a través del tiempo para la zona Pasto y Sapuyes, se observan en las Figuras 1 y 2.

Los dos tipos de alfalfa (moapa y 10-10) no presentaron diferencias en ninguna de las tres localidades, al igual que el maíz forrajero y la remolacha forrajera en la L3, debido a que no hubo un desarrollo completo de estos cultivos por sobresaturación del suelo del sitio de estudio $(\mathrm{p}<0,05)$.

Se observaron diferencias estadísticas significativas $(\mathrm{p}<0,05)$ entre los tratamientos de cada localidad (Cuadro 3). En la L1 y L2 se observó mayor rendimiento de FV para la remolacha forrajera $\left(86,33 \pm 5,12\right.$ y 59,50 $\pm 3,63 \mathrm{t} \mathrm{ha}^{-1}$, respectivamente), por el contrario, en la L3 fue el pasto brasilero $\left(28,00 \pm 3,92 \mathrm{t} \mathrm{ha}^{-1}\right)$; sin embargo, el rendimiento de MS fue diferente, los mayores valores se presentaron en la avena cayuse $\left(14,42 \pm 1,01 \mathrm{t} \mathrm{ha}^{-1}\right)$, la remolacha forrajera $\left(9,91 \pm 0,86 \mathrm{t} \mathrm{ha}^{-1}\right)$ y el pasto brasilero $\left(6,09 \pm 0,60 \mathrm{t} \mathrm{ha}^{-1}\right)$ de las L1, L2 y L3, respectivamente.

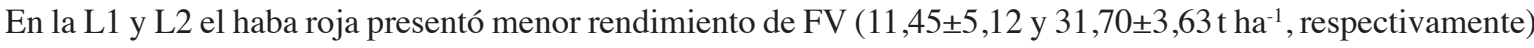
y para la L3 fue el rábano forrajero $\left(6,56 \pm 3,92 \mathrm{t} \mathrm{ha}^{-1}\right)$. Los menores rendimientos de MS se presentaron para el 
Cuadro 2. Manejo agronómico y días a cosecha de diez cultivos forrajeros en tres localidades, dos ubicadas en el Centro de Investigación Obonuco de la Corporación Colombiana de Investigación Agropecuaria (AGROSAVIA), municipio de Pasto, y la tercera localidad en la granja experimental Chimangual de la Universidad de Nariño, Colombia. 2016-2017.

Table 2. Agronomic management and days to harvest of ten fodder crops in three localities, two located in Obonuco Research of the Corporacion Colombiana de Investigacion Agropecuaria (AGROSAVIA), municipality of Pasto, and the third locality in the Chimangual experimental farm of the Universidad de Nariño, Colombia. 2016-2017.

\begin{tabular}{|c|c|c|c|c|c|c|}
\hline Cultivo & $\begin{array}{l}\text { Método y distan- } \\
\text { cia de siembra }\end{array}$ & $\begin{array}{c}\text { Densidad } \\
\text { de siembra }\end{array}$ & Fertilización & Control de plagas & $\begin{array}{c}\text { Control de en- } \\
\text { fermedades }\end{array}$ & $\begin{array}{c}\text { Días a } \\
\text { cosecha }\end{array}$ \\
\hline $\begin{array}{l}\text { Zea mays L. var. } \\
\text { ICA V } 305\end{array}$ & $\begin{array}{c}\text { Semilla-surcos } 0,7 \\
\text { x } 0,1 \mathrm{~m}\end{array}$ & $25 \mathrm{~kg} \mathrm{ha}^{-1}$ & $\begin{array}{c}\text { Siembra: } 200 \mathrm{~kg} \mathrm{ha}^{-1} \\
\text { 10-30-10 + } 10 \mathrm{~kg} \mathrm{ha}^{-1} \\
\text { de menores }\end{array}$ & $\begin{array}{l}\text { Agrotis sp y Spodopte- } \\
\text { ra spp: } 30 \text { dds Clorpiri- } \\
\text { fos }\left(11 \mathrm{ha}^{-1}\right)\end{array}$ & $\begin{array}{l}\text { No se realizó } \\
\text { aplicaciones }\end{array}$ & $235 \mathrm{dds}$ \\
\hline $\begin{array}{l}\text { Avena sativa } \mathrm{L} \text {. } \\
\text { var. Cayuse }\end{array}$ & Semilla-voleo & $80 \mathrm{~kg} \mathrm{ha}^{-1}$ & $\begin{array}{l}\text { Siembra: } 150 \mathrm{~kg} \mathrm{ha}^{-1} 10- \\
30-10+10 \mathrm{~kg} \mathrm{ha}^{-1} \mathrm{de} \\
\text { menores }\end{array}$ & $\begin{array}{l}\text { No se realizó aplica- } \\
\text { ciones }\end{array}$ & $\begin{array}{c}\text { Puccinia gra- } \\
\text { minis: } 90 \mathrm{dds} \\
\text { Propiconazol }(0,5 \\
\left.1 \mathrm{ha}^{-1}\right)\end{array}$ & $150 \mathrm{dds}$ \\
\hline Beta vulgaris $L$. & Semilla-voleo & $7 \mathrm{~kg} \mathrm{ha}^{-1}$ & $\begin{array}{c}\text { Siembra: } 200 \mathrm{~kg} \mathrm{ha}^{-1} 10- \\
30-10+10 \mathrm{~kg} \mathrm{ha}^{-1} \mathrm{de} \\
\text { menores }\end{array}$ & $\begin{array}{l}\text { Agrotis sp y Spodopte- } \\
\text { ra spp: } 30 \text { dds Clorpiri- } \\
\text { fos }\left(11 \mathrm{ha}^{-1}\right)\end{array}$ & $\begin{array}{l}\text { No se realizó } \\
\text { aplicaciones }\end{array}$ & $140 \mathrm{dds}$ \\
\hline $\begin{array}{c}\text { Raphanus sati- } \\
\text { vus L. }\end{array}$ & Semilla-voleo & $7 \mathrm{~kg} \mathrm{ha}^{-1}$ & $\begin{array}{l}\text { Siembra: } 100 \mathrm{~kg} \mathrm{ha} \\
{ }^{1} 10-30-10+10 \mathrm{~kg} \text { de } \\
\text { elementos menores. }\end{array}$ & $\begin{array}{l}\text { Agrotis sp y Spodopte- } \\
\text { ra spp: } 30 \text { dds Clorpiri- } \\
\text { fos }\left(11 \mathrm{ha}^{-1}\right)\end{array}$ & $\begin{array}{l}\text { No se realizó } \\
\text { aplicaciones }\end{array}$ & $\begin{array}{c}84-90 \\
\text { dds }\end{array}$ \\
\hline Phalaris $\mathrm{sp}$ & $\begin{array}{c}\text { Macollas-surcos } \\
0,5 \times 0,5 \mathrm{~m}\end{array}$ & $1 \mathrm{t} \mathrm{ha}^{-1}$ & $\begin{array}{l}\text { Siembra: } 150 \mathrm{~kg} \mathrm{ha}^{-1} \\
10-30-10+10 \mathrm{~kg} \text { de } \\
\text { elementos menores } \\
90 \text { dds: } 30 \mathrm{~kg} \mathrm{ha}^{-1} \text { urea }\end{array}$ & $\begin{array}{l}\text { Agrotis sp y Spodop- } \\
\text { tera spp: } 30 \text { y } 90 \mathrm{dds} \\
\text { Cloririfos }\left(11 \mathrm{ha}^{-1}\right)\end{array}$ & $\begin{array}{c}\text { No se realizó } \\
\text { aplicaciones }\end{array}$ & $\begin{array}{l}200-204 \\
\text { dds }\end{array}$ \\
\hline $\begin{array}{l}\text { Vicia faba } \mathrm{L} \text {. } \\
\text { (haba roja) }\end{array}$ & \multirow{3}{*}{$\begin{array}{c}\text { Semilla-surcos } 0,9 \\
\text { x } 0,5 \mathrm{~m}\end{array}$} & $90 \mathrm{~kg} \mathrm{ha}^{-1}$ & $\begin{array}{l}\text { Siembra: } 100 \mathrm{~kg} \mathrm{ha}^{-1} \\
10-30-10+10 \mathrm{~kg} \mathrm{de} \\
\text { elementos menores }\end{array}$ & $\begin{array}{l}\text { Agrotis sp y Spodopte- } \\
\text { ra spp: } 30 \text { dds Clorpiri- } \\
\text { fos }\left(11 \mathrm{ha}^{-1}\right)\end{array}$ & $\begin{array}{l}\text { Preventivo pu- } \\
\text { driciones radi- } \\
\text { culares: } 45 \text { dds } \\
\text { Carbendazim (1 } \\
\left.\quad 1 \text { ha }^{-1}\right)\end{array}$ & \multirow{3}{*}{$\begin{array}{c}190 \mathrm{a} \\
205 \mathrm{dds}\end{array}$} \\
\hline $\begin{array}{l}\text { Vicia faba } \mathrm{L} \text {. } \\
\text { (haba blanca } \\
\text { común) }\end{array}$ & & $80 \mathrm{~kg} \mathrm{ha}^{-1}$ & \multirow{2}{*}{$\begin{array}{l}90 \text { dds: } 50 \mathrm{~kg} \mathrm{ha}^{-1} 15- \\
15-15\end{array}$} & \multirow{2}{*}{$\begin{array}{l}\text { Liriomyza sp: } 90 \mathrm{dds} \\
\quad\left(200 \mathrm{~g} \mathrm{ha}^{-1}\right)\end{array}$} & $\begin{array}{c}\text { Botrytis fabae: } 90 \\
\text { dds Azoxistrobin } \\
\text { + difeconazol }\end{array}$ & \\
\hline $\begin{array}{l}\text { Vicia faba } \mathrm{L} . \\
\text { (haba alpargata) }\end{array}$ & & $70 \mathrm{~kg} \mathrm{ha}^{-1}$ & & & $\begin{array}{c}\left(500 \mathrm{~cm}^{3} \mathrm{ha}^{-1}\right) \\
105 \mathrm{dds}^{2} \text { Iprodio- } \\
\text { ne }\left(11 \mathrm{ha}^{-1}\right)\end{array}$ & \\
\hline $\begin{array}{l}\text { Medicago sati- } \\
\text { va } \mathrm{L} \text {. var. moapa } \\
\text { Medicago sati- } \\
\text { va } \mathrm{L} \text {. var. } 10-10\end{array}$ & Semilla-voleo & $10 \mathrm{~kg} \mathrm{ha}^{-1}$ & $\begin{array}{l}\text { Siembra: } 200 \mathrm{~kg} \mathrm{ha}^{-1} \\
\text { 10-30-10 + } 5 \mathrm{~kg} \text { de ele- } \\
\text { mentos menores }\end{array}$ & $\begin{array}{l}\text { No se realizaron apli- } \\
\text { caciones }\end{array}$ & $\begin{array}{l}\text { No se realizó } \\
\text { aplicaciones }\end{array}$ & - \\
\hline
\end{tabular}

dds : días después de la siembra / dds: days after sowing.

rábano forrajero $\left(4,65 \pm 0,86\right.$ y $\left.1,14 \pm 0,60 \mathrm{t} \mathrm{ha}^{-1}\right)$ en la $\mathrm{L} 2$ y $\mathrm{L} 3$, respectivamente, y el haba roja $\left(2,38 \pm 1,01 \mathrm{t} \mathrm{ha}^{-1}\right)$ en la L1. Similar a las variables productivas, las variables nutricionales presentaron diferencia estadística significativa $(\mathrm{p}<0,05)$ entre los tratamientos para cada localidad.

En la L1 (Cuadro 4) la remolacha forrajera presentó mayor PC, HEM, DIG y ENL $(17,39 \pm 1,16 \% ; 27,68 \pm 0,74$ $\% ; 69,25 \pm 1,12 \% ; 1,43 \pm 0,25 \mathrm{Mcal} \mathrm{kg}^{-1} \mathrm{MS}$, respectivamente) y el maíz forrajero mayor FDN, FDA y LIG $(61,59 \pm 1,33 \% ; 34,14 \pm 0,91 \% ; 8,17 \pm 0,29 \%$, respectivamente). Mientras que el maíz forrajero presentó menor PC, DIG y ENL $\left(6,92 \pm 1,16 \%, 54,28 \pm 1,12 \%\right.$ y $1,09 \pm 0,25 \mathrm{Mcal} \mathrm{kg}^{-1} \mathrm{MS}$, respectivamente); la remolacha forrajera 


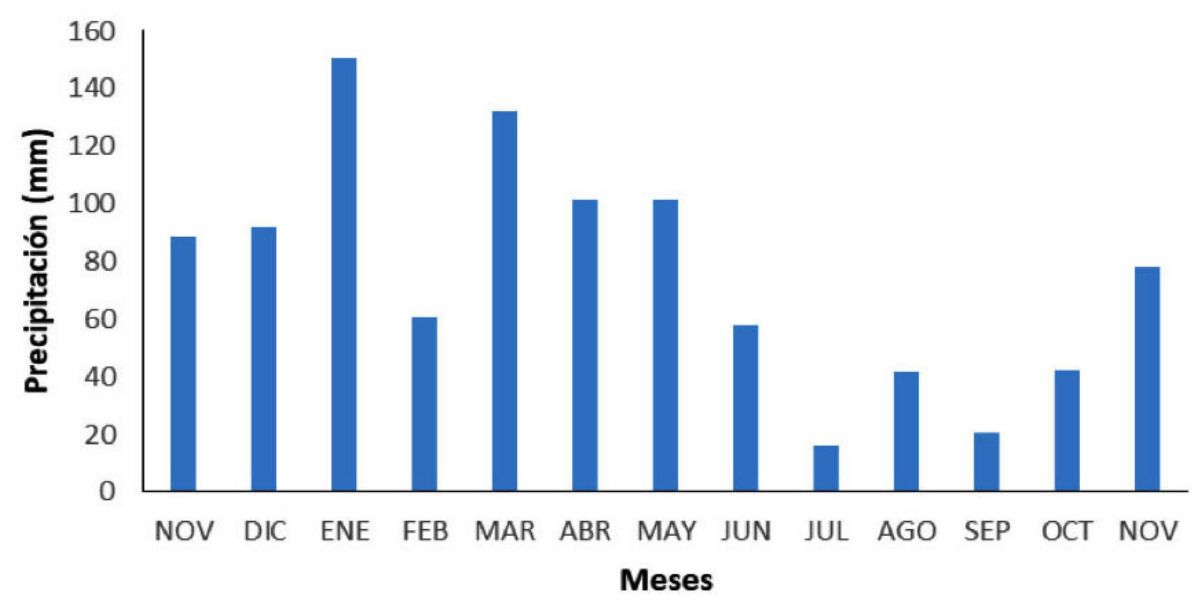

- C.I Obonuco 2016-2017

Figura 1. Precipitación acumulada de noviembre de 2016 a noviembre de 2017, Vintage station pro 2, ubicada en la estación de investigación C.I Obonuco de la Corporación Colombiana de Investigación Agrícola (AGROSAVIA). Pasto, Colombia.

Figure 1. Accumulated precipitation from November 2016 to November 2017, Vintage station pro 2, located at the C.I Obonuco research station of the Corporacion Colombiana de Investigacion Agropecuaria (AGROSAVIA). Pasto, Colombia.

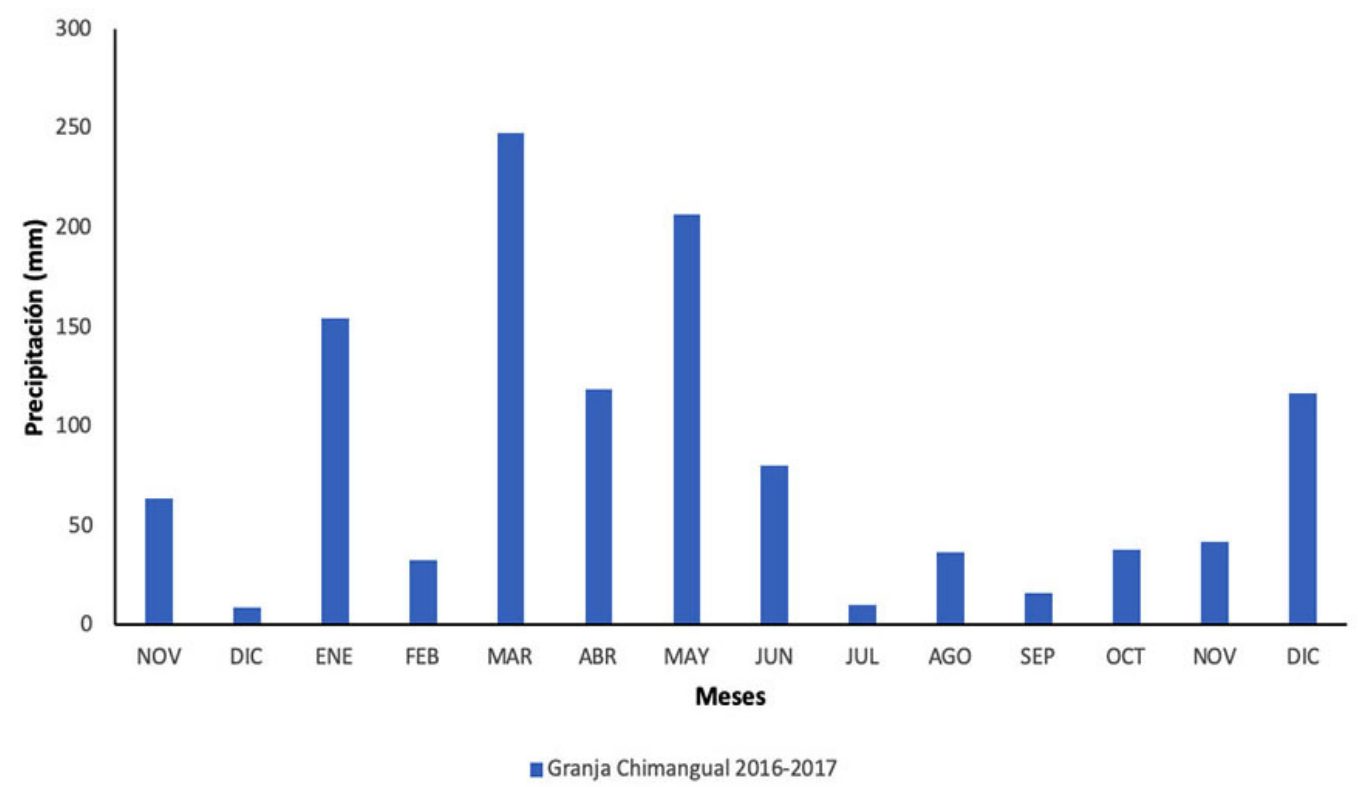

Figura 2. Precipitación acumulada de noviembre de 2016 a diciembre de 2017, Estación Instituto de Hidrología, Meteorología y Estudios Ambientales (IDEAM) 52055020 Tuquerres, Colombia.

Figure 2. Cumulative precipitation from November 2016 to December 2017, Instituto de Hidrologia, Meteorologia y Estudios Ambientales (IDEAM) 52055020 Station Tuquerres, Colombia. 
Cuadro 3. Promedio de variables productivas evaluadas en diez cultivos forrajeros y en tres localidades: L1 y L2 en el Centro de Investigación Obonuco de la Corporación Colombiana de Investigación Agropecuaria (AGROSAVIA), municipio de Pasto, y L3 en la granja experimental Chimangual de la Universidad de Nariño. Colombia, 2016-2017.

Table 3. Average of productive variables evaluated in ten forage crops and in three locations: L1 and L2 at the Obonuco Research Center of the Corporación Colombiana de Investigación Agropecuaria (AGROSAVIA), municipality of Pasto, and L3 at the Chimangual experimental farm of the Universidad de Nariño, Colombia. 2016-2017.

\begin{tabular}{|c|c|c|c|c|c|c|}
\hline \multirow[t]{3}{*}{ Tratamiento } & \multicolumn{2}{|c|}{ L1 } & \multicolumn{2}{|c|}{$\mathbf{L 2}$} & \multicolumn{2}{|c|}{ L3 } \\
\hline & FV & MS & FV & MS & FV & MS \\
\hline & $\left(t h^{-1}\right)$ & $\left(\mathrm{t} \mathrm{ha}^{-1}\right)$ & $\left(t h^{-1}\right)$ & $\left(t h^{-1}\right)$ & $\left(t_{\text {ha }}^{-1}\right)$ & $\left(\mathrm{t} \mathrm{ha}^{-1}\right)$ \\
\hline Maíz ICA V 305 & $65,33^{\mathrm{abc}}$ & $9,46^{\mathrm{ab}}$ & $37,70^{\text {bc }}$ & $6,37^{\mathrm{ab}}$ & - & - \\
\hline Avena cayuse & $64,33^{\mathrm{abc}}$ & $14,42^{\mathrm{a}}$ & $35,00^{\mathrm{bc}}$ & $7,16^{\mathrm{ab}}$ & $18,63^{\text {ab }}$ & $3,19^{\mathrm{ab}}$ \\
\hline Remolacha forrajera & $86,33^{\mathrm{a}}$ & $14,35^{\mathrm{a}}$ & $59,50^{\mathrm{a}}$ & $9,91^{\mathrm{a}}$ & - & - \\
\hline Rábano forrajero & $72,10^{\mathrm{ab}}$ & $10,22^{\mathrm{ab}}$ & $33,10^{\mathrm{c}}$ & $4,65^{\mathrm{b}}$ & $6,56^{\mathrm{b}}$ & $1,14^{\mathrm{b}}$ \\
\hline Pasto brasilero & $69,60^{\mathrm{bc}}$ & $9,77^{\mathrm{ab}}$ & $52,80^{\mathrm{ab}}$ & $8,09^{\mathrm{ab}}$ & $28,00^{\mathrm{a}}$ & $6,09^{\mathrm{a}}$ \\
\hline Haba roja & $11,45^{\mathrm{e}}$ & $2,38^{\mathrm{c}}$ & $31,70^{\mathrm{c}}$ & $6,69^{\mathrm{ab}}$ & $16,50^{\mathrm{ab}}$ & $3,20^{\mathrm{ab}}$ \\
\hline Haba común & $31,56^{\mathrm{de}}$ & $6,53^{\mathrm{bc}}$ & $39,93^{\mathrm{bc}}$ & $8,12^{\mathrm{ab}}$ & $23,49^{\mathrm{a}}$ & $4,47^{\mathrm{a}}$ \\
\hline Haba alpargata & $46,22^{\mathrm{cd}}$ & $9,28^{\mathrm{b}}$ & $39,20^{\mathrm{bc}}$ & $6,61^{\mathrm{ab}}$ & $19,23^{\mathrm{ab}}$ & $3,40^{\mathrm{ab}}$ \\
\hline Alfalfa moapa & - & - & - & - & - & - \\
\hline Alfalfa $10-10$ & - & - & - & - & - & - \\
\hline
\end{tabular}

a-b-c-d Letras diferentes entre columnas indican diferencia estadística significativa (p<0,05). L1: localidad 1, L2: localidad 2, L3: localidad 3. FV: forraje verde, MS: materia seca. (-) no se obtuvieron datos porque los cultivos no se desarrollaron satisfactoriamente /a-b-c-d Different letters between columns indicate significant statistical difference ( $<<0.05)$. L1: locality 1, L2: locality 2, L3: locality 3. FV: greed feed, MS: dry matter. (-) no data were obtained because crops did not grow satisfactorily.

menor FDN, FDA y LIG $(40,79 \pm 1,33 \%, 13,11 \pm 0,91 \%$ y $2,70 \pm 0,29 \%)$, y el rábano forrajero menor HEM $(16,01 \pm 0,74 \%)$.

En la L2 (Cuadro 5), el haba común presentó mayor PC, DIG y ENL $(20,24 \pm 0,85 \% ; 70,20 \pm 2,84 \%$ y $1,45 \pm 0,05 \mathrm{Mcal} \mathrm{kg}^{-1} \mathrm{MS}$, respectivamente), el maíz forrajero mayor FDN, FDA, LIG $(62,18 \pm 2,22 \% ; 35,96 \pm 2,41$ $\% ; 9,42 \pm 1,07 \%$, respectivamente), el pasto brasilero mayor HEM $(29,52 \pm 0,64)$. En cambio, la avena cayuse presentó menor PC $(4,30 \pm 0,85 \%)$, el haba común menor FDN $(32,01 \pm 2,22 \%)$, la remolacha forrajera menor FDA y LIG $(13,93 \pm 2,41 \%$ y $3,24 \pm 1,07 \%$, respectivamente), el haba roja menor HEM $(14,60 \pm 0,64 \%)$, y la avena cayuse menor DIG y ENL (53,11 $\pm 2,84 \%$ y $1,07 \pm 0,05 \mathrm{Mcal} \mathrm{kg} \mathrm{MS}^{-1}$, respectivamente).

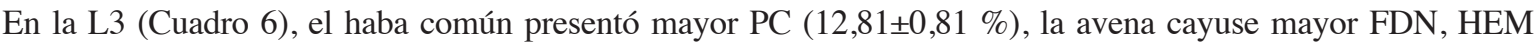
y DIG $(53,01 \pm 2,82 \% ; 23,29 \pm 1,40 \%$ y $73,49 \pm 4,09 \%)$, el rábano forrajero mayor FDA y LIG $(29,94 \pm 2,72 \%$ y $7,70 \pm 0,69$, respectivamente) y la avena cayuse, el haba roja y el haba común presentaron mayor ENL $(1,49 \pm 0,09$ Mca $\left.\mathrm{kg}^{-1} \mathrm{MS}\right)$. En cambio, la avena cayuse presentó menor PC $(2,80 \pm 0,81 \%)$, el haba roja menor FDN y FDA $(28,52 \pm 2,82$ $\%$ y $15,50 \pm 2,72 \%$, respectivamente), el haba común menor LIG $(4,63 \pm 0,69 \%)$, el haba alpargata menor HEM $(12,92 \pm 1,40 \%)$ y el rábano forrajero menor DIG y $\operatorname{ENL}\left(55,35 \pm 4,09 \%\right.$ y $1,12 \pm 0,09 \mathrm{Mcal} \mathrm{kg}^{-1} \mathrm{MS}$, respectivamente).

En el caso de los cultivos de maíz y remolacha no se logró un desarrollo adecuado para alcanzar la etapa fenológica de cosecha, debido a problemas de sobresaturación de agua en los suelos sobre los que se llevó a cabo el ensayo, para las variedades de alfalfa en las tres localidades el método de siembra utilizado (voleo) no permitió realizar un control adecuado de arvenses durante la etapa de germinación, como consecuencia el porcentaje de sobrevivencia de la especie fue nulo. 
Cuadro 4. Promedio de variables nutricionales evaluadas en diez cultivos forrajeros en la localidad L1 en el Centro de Investigación Obonuco de la Corporación Colombiana de Investigación Agropecuaria (AGROSAVIA), municipio de Pasto. Colombia. $2016-2017$.

Table 4. Average of nutritional variables evaluated in ten forage crops in the L1 locality in the Obonuco Research Center of the Corporacion Colombiana de Investigacion Agropecuaria (AGROSAVIA), municipality of Pasto. Colombia. 2016-2017.

\begin{tabular}{|c|c|c|c|c|c|c|c|}
\hline Tratamiento & $\begin{array}{l}\text { PC } \\
(\%)\end{array}$ & $\begin{array}{c}\text { FDN } \\
(\%)\end{array}$ & $\begin{array}{c}\text { FDA } \\
(\%)\end{array}$ & $\begin{array}{l}\text { LIG } \\
(\%)\end{array}$ & $\begin{array}{c}\text { HEM } \\
(\%)\end{array}$ & $\begin{array}{l}\text { DIG } \\
(\%)\end{array}$ & $\begin{array}{c}\text { ENL } \\
\left(\text { Mcal kg MS }^{-1}\right)\end{array}$ \\
\hline Maíz ICA V 305 & $6,92^{\mathrm{d}}$ & $61,59^{\mathrm{a}}$ & $34,14^{\mathrm{d}}$ & $8,17^{\mathrm{d}}$ & $27,45^{\mathrm{a}}$ & $54,28^{\mathrm{d}}$ & $1,09^{d}$ \\
\hline Avena cayuse & $7,30^{\mathrm{cd}}$ & $58,12^{\mathrm{a}}$ & $31,81^{\mathrm{cd}}$ & $6,53^{\mathrm{bc}}$ & $26,30^{\mathrm{a}}$ & $55,32^{\mathrm{d}}$ & $1,12^{\mathrm{d}}$ \\
\hline Remolacha forrajera & $17,39^{\mathrm{a}}$ & $40,79^{c}$ & $13,11^{\mathrm{a}}$ & $2,70^{\mathrm{a}}$ & $27,68^{\mathrm{a}}$ & $69,25^{\mathrm{a}}$ & $1,43^{\mathrm{a}}$ \\
\hline Rábano forrajero & $12,97^{\mathrm{abc}}$ & $42,71^{\mathrm{bc}}$ & $26,69^{b}$ & $5,83^{\mathrm{bc}}$ & $16,01^{\mathrm{c}}$ & $61,46^{\mathrm{bc}}$ & $1,25^{\mathrm{bc}}$ \\
\hline Pasto brasilero & $11,92^{\text {abcd }}$ & $58,91^{\mathrm{a}}$ & $31,86^{\mathrm{cd}}$ & $6,81^{\mathrm{cd}}$ & $27,05^{\mathrm{a}}$ & $58,99^{\text {bcd }}$ & $1,20^{\mathrm{bcd}}$ \\
\hline Haba roja & $9,43^{\text {bcd }}$ & $43,59^{\mathrm{bc}}$ & $25,16^{\mathrm{b}}$ & $5,09^{\mathrm{b}}$ & $18,43^{\mathrm{bc}}$ & $59,12^{\text {bcd }}$ & $1,20^{\mathrm{bcd}}$ \\
\hline Haba común & $7,48^{\mathrm{cd}}$ & $49,13^{\mathrm{b}}$ & $28,98^{\mathrm{bc}}$ & $6,24^{\mathrm{bc}}$ & $20,15^{\mathrm{b}}$ & $56,35^{\mathrm{cd}}$ & $1,14^{\mathrm{cd}}$ \\
\hline Haba alpargata & $14,24^{\mathrm{ab}}$ & $43,38^{\mathrm{bc}}$ & $26,93^{\mathrm{b}}$ & $6,49^{\mathrm{bc}}$ & $16,45^{\text {bc }}$ & $62,40^{\mathrm{b}}$ & $1,27^{\mathrm{b}}$ \\
\hline Alfalfa moapa & - & - & - & - & - & - & - \\
\hline Alfalfa $10-10$ & - & - & - & - & - & - & - \\
\hline
\end{tabular}

a-b-c-d Letras diferentes entre columnas indican diferencia estadística significativa $(\mathrm{p}<0,05)$. PC: proteína cruda, FDN: fibra en detergente neutro, FDA: fibra en detergente acido, LIG: lignina, HEM: hemicelulosa, DIG: digestibilidad de la materia seca, ENL: energía neta de

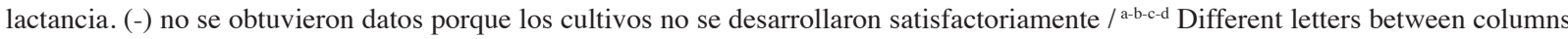
indicate significant statistical difference $(\mathrm{p}<0.05)$. PC: crude protein, FDN: fiber in neutral detergent, FDA: acid detergent fiber, LIG: lignin, HEM: hemicellulose, DIG: dry matter digestibility, ENL: lactation net energy. (-) no data were obtained because the crops did not grow satisfactorily.

Cuadro 5. Promedio de variables nutricionales evaluadas en diez cultivos forrajeros en la localidad L2 en el Centro de Investigación Obonuco de la Corporación Colombiana de Investigación Agropecuaria (AGROSAVIA), municipio de Pasto. Colombia. $2016-2017$.

Table 5. Average of nutritional variables evaluated in ten forage crops in the L2 locality in the Obonuco Research Center of the Corporacion Colombiana de Investigacion Agropecuaria (AGROSAVIA), municipality of Pasto. Colombia. 2016-2017.

\begin{tabular}{|c|c|c|c|c|c|c|c|}
\hline Tratamiento & $\begin{array}{l}\text { PC } \\
(\%)\end{array}$ & $\begin{array}{c}\text { FDN } \\
(\%) \\
\end{array}$ & $\begin{array}{c}\text { FDA } \\
(\%) \\
\end{array}$ & $\begin{array}{l}\text { LIG } \\
(\%) \\
\end{array}$ & $\begin{array}{c}\text { HEM } \\
(\%) \\
\end{array}$ & $\begin{array}{l}\text { DIG } \\
(\%)\end{array}$ & $\begin{array}{c}\text { ENL } \\
\left(\text { Mcal kgMS }^{-1}\right) \\
\end{array}$ \\
\hline Maíz ICA V 305 & $5,34^{\mathrm{c}}$ & $62,18^{\mathrm{a}}$ & $35,96^{\mathrm{d}}$ & $9,42^{\mathrm{b}}$ & $26,22^{\mathrm{b}}$ & $64,41^{\text {ab }}$ & $1,27^{\mathrm{abc}}$ \\
\hline Avena cayuse & $4,30^{\mathrm{c}}$ & $58,55^{\mathrm{a}}$ & $31,23^{\mathrm{cd}}$ & $7,35^{\mathrm{ab}}$ & $27,32^{\mathrm{ab}}$ & $53,11^{\mathrm{b}}$ & $1,07^{\mathrm{c}}$ \\
\hline Remolacha forrajera & $15,18^{\mathrm{b}}$ & $40,81^{\mathrm{b}}$ & $13,93^{\mathrm{a}}$ & $3,24^{\mathrm{a}}$ & $26,87^{\mathrm{a}}$ & $67,23^{\mathrm{ab}}$ & $1,38^{\mathrm{ab}}$ \\
\hline Rábano forrajero & $12,97^{\mathrm{b}}$ & $42,71^{\mathrm{b}}$ & $26,69^{\mathrm{bcd}}$ & $5,83^{\mathrm{ab}}$ & $16,01^{\mathrm{c}}$ & $61,46^{\mathrm{ab}}$ & $1,25^{\mathrm{abc}}$ \\
\hline Pasto brasilero & $6,17^{\mathrm{c}}$ & $57,22^{\mathrm{a}}$ & $27,70^{\text {bcd }}$ & $5,98^{\mathrm{ab}}$ & $29,52^{\mathrm{a}}$ & $55,71^{\mathrm{b}}$ & $1,13^{\mathrm{bc}}$ \\
\hline Haba roja & $14,16^{\mathrm{b}}$ & $40,10^{\mathrm{b}}$ & $25,50^{\mathrm{abcd}}$ & $7,58^{\mathrm{ab}}$ & $14,60^{\mathrm{c}}$ & $62,77^{\mathrm{ab}}$ & $1,28^{\mathrm{abc}}$ \\
\hline Haba común & $20,24^{\mathrm{a}}$ & $32,01^{\mathrm{b}}$ & $17,30^{\mathrm{ab}}$ & $4,81^{\text {ba }}$ & $14,70^{\mathrm{c}}$ & $70,20^{\mathrm{a}}$ & $1,45^{\mathrm{a}}$ \\
\hline Haba alpargata & $15,31^{\mathrm{b}}$ & $38,19^{b}$ & $21,25^{\mathrm{abc}}$ & $5,30^{\mathrm{ab}}$ & $16,94^{\mathrm{c}}$ & $65,03^{\mathrm{ab}}$ & $1,33^{\mathrm{abc}}$ \\
\hline Alfalfa moapa & - & - & - & - & - & - & - \\
\hline Alfalfa 10-10 & - & - & - & - & - & - & - \\
\hline
\end{tabular}

a-b-c-d Letras diferentes entre columnas indican diferencia estadística significativa $(\mathrm{p}<0,05)$. PC: proteína cruda, FDN: fibra en detergente neutro, FDA: fibra en detergente acido, LIG: lignina, HEM: hemicelulosa, DIG: digestibilidad de la materia seca, ENL: energía neta de lactancia. (-) no se obtuvieron datos porque los cultivos no se desarrollaron satisfactoriamente / a-b-c-d Different letters between columns indicate significant statistical difference $(\mathrm{p}<0.05)$. PC: crude protein, FDN: fiber in neutral detergent, FDA: acid detergent fiber, LIG: lignin, HEM: hemicellulose, DIG: dry matter digestibility, ENL: lactation net energy. (-) no data were obtained because the crops did not grow satisfactorily. 
Cuadro 6. Promedio de variables nutricionales evaluadas en diez cultivos forrajeros en la localidad L3 en la granja experimental Chimangual de la Universidad de Nariño, Colombia. 2016-2017.

Table 6. Average of nutritional variables evaluated in ten forage crops in the L3 locality in the Chimangual experimental farm of the University de Nariño, Colombia. 2016-2017.

\begin{tabular}{|c|c|c|c|c|c|c|c|}
\hline Tratamiento & $\begin{array}{l}\text { PC } \\
(\%)\end{array}$ & $\begin{array}{c}\text { FDN } \\
(\%)\end{array}$ & $\begin{array}{l}\text { FDA } \\
(\%)\end{array}$ & $\begin{array}{l}\text { LIG } \\
(\%)\end{array}$ & $\begin{array}{c}\text { HEM } \\
(\%)\end{array}$ & $\begin{array}{l}\text { DIG } \\
(\%)\end{array}$ & $\begin{array}{c}\text { ENL } \\
\left(\text { Mcal kg MS-1) }^{-1}\right)\end{array}$ \\
\hline Maíz ICA V 305 & - & - & - & - & - & - & - \\
\hline Avena cayuse & $3,80^{\mathrm{b}}$ & $53,01^{\mathrm{a}}$ & $29,72^{\mathrm{ab}}$ & $7,34^{\mathrm{b}}$ & $23,29^{\mathrm{a}}$ & $73,49^{\mathrm{a}}$ & $1,49^{\mathrm{a}}$ \\
\hline Remolacha forrajera & - & - & - & - & - & - & - \\
\hline Rábano forrajero & $6,60^{\mathrm{b}}$ & $46,98^{\mathrm{ab}}$ & $29,94^{\mathrm{ab}}$ & $7,70^{\mathrm{b}}$ & $17,04^{\mathrm{ab}}$ & $55,35^{\mathrm{a}}$ & $1,12^{\mathrm{a}}$ \\
\hline Pasto brasilero & $11,80^{\mathrm{a}}$ & $52,71^{\mathrm{a}}$ & $29,44^{\mathrm{b}}$ & $7,39^{\mathrm{b}}$ & $23,27^{\mathrm{a}}$ & $59,66^{\mathrm{a}}$ & $1,21^{\mathrm{a}}$ \\
\hline Haba roja & $12,70^{\mathrm{a}}$ & $28,52^{\mathrm{c}}$ & $15,50^{\mathrm{a}}$ & $4,93^{\mathrm{a}}$ & $13,02^{\mathrm{b}}$ & $71,64^{a}$ & $1,49^{\mathrm{a}}$ \\
\hline Haba común & $12,81^{\mathrm{a}}$ & $29,93^{\mathrm{c}}$ & $15,59^{\mathrm{a}}$ & $4,63^{\mathrm{a}}$ & $14,34^{b}$ & $71,72^{\mathrm{a}}$ & $1,49^{\mathrm{a}}$ \\
\hline Haba alpargata & $11,96^{\mathrm{a}}$ & $37,51^{\mathrm{bc}}$ & $24,59^{\mathrm{ab}}$ & $7,39^{\mathrm{b}}$ & $12,92^{\mathrm{b}}$ & $67,53^{\mathrm{a}}$ & $1,39^{\mathrm{a}}$ \\
\hline Alfalfa moapa & - & - & - & - & - & - & - \\
\hline Alfalfa $10-10$ & - & - & - & - & - & - & - \\
\hline
\end{tabular}

a-b-c-d Letras diferentes entre columnas indican diferencia estadística significativa $(\mathrm{p}<0,05)$. PC: proteína cruda, FDN: fibra en detergente neutro, FDA: fibra en detergente acido, LIG: lignina, HEM: hemicelulosa, DIG: digestibilidad de la materia seca, ENL: energía neta de

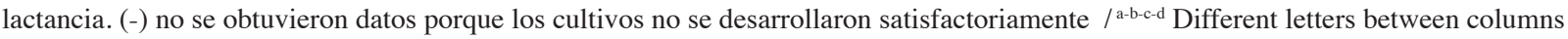
indicate significant statistical difference ( $\mathrm{p}<0.05)$. PC: crude protein, FDN: fiber in neutral detergent, FDA: acid detergent fiber, LIG: lignin, HEM: hemicellulose, DIG: dry matter digestibility, ENL: lactation net energy. (-) no data were obtained because the crops did not grow satisfactorily.

\section{Discusión}

La remolacha forrajera superó los rendimientos en la mayoría de los cultivos de granos, ya que obtuvo los mayores rendimientos en FV en las L1 y L2 (Cuadro 1), resultados que coinciden con otros estudios (Hoffmann et al., 2009; Evans y Messerschmidt, 2017). Este rendimiento se debe probablemente al hecho de que es un cultivo que no tiene etapas de crecimiento susceptibles a condiciones ambientales desfavorables como la floración y el llenado de granos que son muy importantes en el rendimiento final de estos (Hoffmann et al., 2009).

La avena cayuse obtuvo el mayor rendimiento de MS en la L1 (Cuadro 1), pero inferior en 15,26 t ha-1 a lo reportado por Argote y Halanoca (2007), en un estudio realizado en el altiplano del departamento de Puno, Perú (29,68 tha-1 MS) y superior a los encontrados por Bolaños et al. (2003), para la variedad obonuco avenar y avena cayuse (7,0 y 6,62 t ha-1 MS, respectivamente), sin embargo, estos últimos autores justificaron que el mejor rendimiento obtenido en obonuco avenar fue debido a su precocidad, ya que tanto para pastorear, ensilar y cosechar el grano, se obtuvo cincuenta días más temprano que la avena cayuse, además fue moderadamente resistente a plagas y patógenos, lo que ocasionó una disminución en los costos de producción.

El mayor rendimiento de MS en la L2 se obtuvo en la remolacha forrajera (Cuadro 1) con una densidad de 10 plantas $\mathrm{m}^{-2}$, un valor inferior al reportado por Edwards et al. (2014), quienes obtuvieron rendimientos para este cultivo de 18,5 y $21,8 \mathrm{t} \mathrm{ha}^{-1} \mathrm{MS}$, para densidades de 6 y 10 plantas $\mathrm{m}^{-2}$, respectivamente.

Los mayores rendimientos de FV y MS los presentó el pasto brasilero en la L3, estos difirieron de los encontrados por Salas y Córdoba (2013), y Eraso et al. (2014), quienes reportaron rendimientos inferiores de FV (18,4 y $15,9 \mathrm{tha}^{-1}$, respectivamente) y MS (4,2 y $3,16 \mathrm{tha}^{-1}$, respectivamente), sembrado por rizomas a una distancia 
de 0,30 m. Esta mayor producción se puede explicar por los niveles favorables de precipitación (1200 mm), a diferencia de los estudios anteriormente mencionados con 800 y $659 \mathrm{~mm}$, respectivamente, lo que concuerda con lo expresado por Eraso et al. (2014), quienes afirmaron que esta especie requiere precipitaciones anuales superiores a $1000 \mathrm{~mm}$ para desarrollarse adecuadamente.

Se consideró alto el porcentaje de PC encontrado en toda la planta de la remolacha forrajera de la L1 (Cuadro 2 ), teniendo en cuenta que es una especie con raíces altas en energía, pero posee un alto contenido de PC en sus hojas, lo que mejora la calidad nutricional al momento de cosechar la planta completa (Reta et al., 2008; Biondo et al., 2014). Sin embargo, los valores de PC fueron inferiores a los obtenidos por Reta et al. (2008), quienes reportaron para planta completa $26,7 \%$, parte aérea $28,1 \%$ y raíz $23 \%$, lo que se puede relacionar con los días a cosecha, debido a que en el anterior trabajo se cosechó a los 104 días, mientras que en el presente estudio fue a los 140 días.

El haba común de las L2 y L3 (Cuadro 3 y 4) presentó los mayores contenidos de PC, sin embargo, se consideraron bajos para ser una leguminosa, así lo afirmaron Martínez et al. (2005b), quienes encontraron 15,5 $\%$ como promedio para diez variedades de haba, de igual forma Martínez et al. (2005a), de-la-Roza et al. (2008) y Baizán et al. (2015) reportaron valores para toda la planta en monocultivo de 18,9 \%, 17,8 \% y 16,73\%, respectivamente. Este bajo contenido de $\mathrm{PC}$ se puede relacionar al alto contenido de agua en estado de vaina con grano como fue cosechado en este estudio (20\% de MS), lo que generó altos lixiviados al momento del corte, por consiguiente, pérdida de nutrientes (Martínez et al., 2005a; De-la-Roza et al., 2008).

De acuerdo con el contenido de PC, según la clasificación de Núñez et al. (2009), la mayoría de las especies evaluadas se encontraron entre una clasificación mala (8-12\%) y regular (12-15\%), aunque la remolacha forrajera y el haba alpargata de la L1 se clasificaron como buenos (15-18\%) y el haba común de la L2 fue la única especie que se clasificó como excelente (>18\%).

El cultivo de maíz Ica V 305 presentó los valores más altos de FDN y FDA en las L1 y L2 (Cuadro 2 y 3 ), siendo superiores a los reportados por Reta et al. (2010) para primavera y verano (48,8 \%; $29,1 \%$ y 56,1\%; 34,6 $\%$, respectivamente). De igual forma, superior a los encontrados por Moreno et al. (2017) para FDN y FDA con fertilización orgánica e inorgánica de 53,5\%;35,9\% y 42,6\%; 27,2\%, respectivamente, cosechado a los 112 días, en comparación con los 235 días en promedio para este estudio, lo que pudo generar los mayores contenidos de fibra. Esta diferencia en el ciclo productivo se relaciona principalmente a la altura sobre el nivel del mar (Moreno et al., 2017), ya que las tres localidades presentaron una altura promedio de $2950 \mathrm{msnm}$ y en la del estudio anteriormente nombrado, fue de $1100 \mathrm{msnm}$.

La avena cayuse de la L3 fue ligeramente inferior en 3,29\% al promedio de FDN de dieciocho variedades de avena forrajera evaluadas por Kafilzadeh y Heidary (2013), y superior al 46,97 \% reportado por Mamani (2016), en estos trabajos y en el presente estudio, se realizó la cosecha en estado de grano lechoso-pastoso. Estas diferencias se pueden explicar por los materiales genéticos utilizados en cada investigación y las condiciones agroclimáticas.

El rábano forrajero en la L3 (Cuadro 4) presentó el mayor contenido de FDA, siendo similar a 28,99, obtenido por Ulrich (2018). De acuerdo con este porcentaje se puede considerar de buena calidad, debido a que se encuentra por debajo del $35 \%$ (Zamora et al., 2016).

La remolacha forrajera en la L1 presentó el contenido de FDN más bajo (Cuadro 2), pero fue superior al compararlo con el reportado por Reta et al. (2008), quienes obtuvieron 31,7 \% con temperaturas promedios que incrementaron de 15 a $23{ }^{\circ} \mathrm{C}$ entre la emergencia y la cosecha. Este aumento de temperatura disminuyó el ciclo productivo de 105 a 73 días, a diferencia del presente estudio, en el cual la cosecha se realizó a los 140 días con una temperatura promedio de $12{ }^{\circ} \mathrm{C}$. Según lo anterior se puede relacionar que a mayor temperatura se puede obtener un desarrollo acelerado del cultivo de la remolacha forrajera, logrando varios ciclos durante el año. Silva et al. (2011), afirmaron que el desarrollo de las raíces se ve favorecido a una temperatura entre 15 y $23{ }^{\circ} \mathrm{C}$, mientras que las hojas entre 20 y $30^{\circ} \mathrm{C}$. 
El haba común y el haba roja presentaron los menores contenidos de FDN en las L2 y L3 (Cuadro 3 y 4), los cuales fueron superiores a 27,68 \% (de-la-Roza et al., 2008), pero inferiores a 51,05\% (Baizán et al., 2015) y 38,9 $\%$ (Martínez et al., 2005a) reportados en la literatura. Sin embargo, Martínez et al. (2005a) en su estudio, el cual fue realizado con fines de buscar cultivos forrajeros alternativos para ensilar, afirmaron que este proceso permite que el cultivo de haba pierda agua, por consiguiente, pérdida de nutrientes, lo que disminuye la calidad nutricional, debido a que se aumenta el contenido de FDN (38,9\% vs 59,8 \%) y baja la digestibilidad de la misma, a pesar de esto, afirmaron que este cultivo es una buena alternativa para ensilar.

En la L1 y L2 la remolacha forrajera presentó los más bajos contenidos de FDA (Cuadro 2 y 3), inferiores a lo reportado por Reta et al. (2008), quienes encontraron 20,5\% a los 73 días a cosecha, con una diferencia de 67 días con respecto al presente estudio. Esto difiere de lo que afirmó Mamani (2016), quien definió que el contenido de FDN al igual que el FDA está dado por la maduración de los forrajes, a mayor madurez mayor contenido de estos componentes. En la L3 el más bajo porcentaje de FDA lo presentó el haba roja, el cual estuvo por debajo de 38,46 $\%$, contenido reportado por Baizán et al. (2015).

Las tres variedades de haba (roja, común, alpargata) de las L2 y L3 se clasificaron como excelente, debido a que presentaron porcentajes de FDN inferiores a $40 \%$, y el resto de las especies como buenas, regulares y malas (Núñez et al., 2009). Los altos niveles de FDN en la mayoría de las especies están generalmente asociados con bajos niveles de consumo de alimento por el animal (Salmerón et al., 2003); sin embargo, la fibra es un compuesto de gran relevancia en la dieta de los rumiantes, debido a que juega un papel importante en el mantenimiento del pH ruminal, estimula la rumia, la cual es imprescindible para la producción de saliva y es la sustancia que actúa como neutralizante a nivel de rumen, evitando la reducción del pH por a la producción de ácidos generados por los procesos de fermentación en el rumen; los forrajes más toscos generan una mayor rumia y por lo tanto, un mayor contenido de grasa en leche, por esta razón, se sugiere que la dieta de los rumiantes presente un mínimo de $28 \%$ de FDN (Ramos et al., 1998; Gallegos et al., 2012).

El maíz Ica V 305 presentó el mayor contenido de LIG en la L1 y L2 (Cuadro 2 y 3), contenidos menores a los reportados por Ruiz et al. (2006), quienes reportaron un promedio de LIG de 15,36 \% para siete híbridos, diferencias relacionadas principalmente al ciclo productivo, a los factores ambientales, características físicas (relación hoja - tallo) y genéticas (Núñez et al., 2006; Ruiz et al., 2006). El haba común fue la especie con mayor contenido de LIG en la L3 (Cuadro 4), pero fue inferior a 6,5\% y 7,0 \%, valores reportados por Reta et al. (2008), quienes reportaron estos contenidos a 96 y 106 días de cosecha, respectivamente, tiempo menor al obtenido en el presente estudio, debido a que se tuvo un promedio de 202 días a cosecha para las tres variedades de haba en las tres localidades. Los menores contenidos de LIG se presentaron en remolacha forrajera en la L1 y L2 y el rábano forrajero en la L3 (Cuadro 2, 3 y 4); estos valores se encuentran por debajo de lo reportado por Reta et al. (2008) para remolacha $(4,1 \%)$, y similar al reportado por Ulrich (2018) para rábano $(7,18 \%)$.

La remolacha forrajera presentó el más alto contenido de HEM en la L1 (Cuadro 2), superior a lo reportado por Reta et al. (2008), quienes encontraron 11,2 \% a los 104 días de cosecha. En la L2 y L3 las especies que presentaron mayor contenido de HEM fueron el pasto brasilero y avena cayuse, respectivamente (Cuadro 3 y 4). El contenido de HEM en el pasto brasilero fue similar al 27,8 \% encontrado por Fulkerson et al. (2007). Kafilzadeh y Heidary (2013) y Mamani (2016), obtuvieron contenidos promedios inferiores de HEM para avena forrajera de 20,6 \% y $18,19 \%$, respectivamente. Los contenidos de HEM varían de acuerdo con el contenido de FDN de cada especie (Fulkerson et al., 2007; Mamani, 2016). El rábano forrajero obtuvo el más bajo contenido de HEM en la L1 (Cuadro 2), inferior al estudio realizado por Ulrich (2018), quien encontró contenidos de HEM de 24,26\%, respectivamente. Las habas roja y alpargata de las L2 y L3, respectivamente, presentaron los contenidos de HEM más bajos (Cuadro 3 y 4). Baizán et al. (2015) reportaron contenidos de HEM de 12,59 \%, similar al haba alpargata.

La remolacha forrajera presentó los mayores porcentajes de DIG en la L1 (Cuadro 2), esto se ve relacionado con el alto contenido de azúcar, a la cual se le estimó una digestibilidad cercana a la totalidad, por lo tanto, se 
esperaba que fuera muy alta (Lanzas et al., 2007; Evans y Messerschmidt, 2017). Además, se ve relacionada con que los rumiantes prefieren los forrajes y suplementos dulces (Provenza, 1995; Forbes, 2007), reflejándose en un consumo casi completo de 99,6\% (Edwards et al., 2014). Es de anotar, que la FDA es uno de los compuestos más relacionado con la digestibilidad de los forrajes porque está constituida por celulosa, lignina y proteínas (Castillo et al., 2009). La alimentación con dietas altas en azúcar aumenta la ingesta de MS, la digestibilidad de la fibra y el rendimiento de grasa de la leche; estas características nutricionales permiten utilizar alimentos con alto contenido de azúcar como fuente de energía alternativa para las vacas lecheras, contribuyendo a aumentar la densidad energética de la dieta con un riesgo reducido de acidosis del rumen (Broderick y Radloff, 2004; Broderick et al., 2008; Oba, 2011).

El haba común en la L2 presentó el mayor porcentaje de digestibilidad (Cuadro 3). Se ha reportado un porcentaje de DIG menor al encontrado en este estudio (54,59 \% y 51,27 \%, respectivamente), en las mismas condiciones agroclimáticas con diferentes variedades (Baizán et al., 2015; Martínez et al., 2017). Una alta DIG en haba, similar a la soya, la cual es una de las fuentes de proteína más utilizada en la suplementación de rumiantes obtuvieron (Osmane et al., 2017). La avena cayuse en la L3 presentó el mayor porcentaje de digestibilidad (Cuadro 4); este porcentaje fue superior a los promedios 57,7 \% (Kafilzadeh y Heidary, 2013) y 66,48 \% (Mamani, 2016). Estas diferencias se relacionan principalmente al contenido de FDN y FDA de los forrajes, y al material genético (Castillo et al., 2009; Mamani, 2016). La digestibilidad de un forraje está correlacionada negativamente con la concentración de LIG del mismo (Jung y Deetz, 1993). Sin embargo, de acuerdo con el porcentaje de DIG obtenido en el presente estudio, Núñez et al. (2009), clasificaron la remolacha forrajera de calidad regular y el haba común y la avena cayuse como forraje de buena calidad.

La remolacha forrajera presentó el mayor aporte de ENL en la L1 (Cuadro 2); superior en 0,23 Mcal kg MS-1 a la reportada por Reta et al. (2008), esto debido posiblemente a los altos porcentajes de PC, HEM y DIG. La ENL es uno de los componentes de mayor importancia en la calidad nutricional de los forrajes, la cual está dada por las concentraciones de proteína cruda, fibra detergente neutro, carbohidratos no fibrosos y de la digestibilidad (Núñez et al., 2006; Schwab et al., 2003).

En la L2 el haba común y en la L3 las habas común y roja y avena cayuse, presentaron los más altos contenidos de ENL. Estos contenidos fueron mayores a los obtenidos por Reta et al. (2008), quienes reportaron 1,27 Mcal $\mathrm{kg} \mathrm{MS}^{-1}$ para el cultivo de haba a los 96 días de cosecha en comparación con 202 días para este estudio. Se han reportado mayores contenidos de ENL para haba (1,92, 2,69 y 2,53 $\mathrm{Mcal} \mathrm{kg}^{-1} \mathrm{MS}$, respectivamente), a pesar de que presentaron menores contenidos de proteína (16,73\%, 15,6 \% y 15,5\%, respectivamente) (Baizán et al., 2015; Martínez et al., 2005b; De-la-Roza et al., 2008). La avena cayuse presentó un mayor contenido de ENL al compararlo con lo obtenido por Mamani (2016), quien encontró $1,33 \mathrm{Mcal} \mathrm{kg}^{-1} \mathrm{MS}$; se asume principalmente a la cantidad de grano contenido al momento de la cosecha.

En este parámetro, la mayoría de las especies evaluadas en estudio, fueron buenos y regulares de acuerdo a la clasificación de Núñez et al. (2009).

\section{Conclusiones}

Las tres variedades de haba (roja, común y alpargata) y la remolacha forrajera, presentaron mejor rendimiento productivo y calidad nutricional, principalmente en el contenido de PC, ENL y DIG, las cuales son las características nutritivas de consideración en la formulación de alimentos para rumiantes productores de leche, por lo que representan una alternativa en los sistemas de lechería especializada del trópico alto del departamento de Nariño. 


\section{Agradecimientos}

Los autores agradecen en especial a la Corporación Colombiana de Investigación Agropecuaria (AGROSAVIA) y al macroproyecto denominado "Mejoramiento de la oferta forrajera, optimización de sistemas de alimentación y aseguramiento de la calidad e inocuidad de la leche en el trópico alto del departamento de Nariño", ejecutado mediante recursos del Sistema General de Regalías.

\section{Literatura citada}

Anzola, H., H. Durán, J. Ricón, J. Martínez, y J. Restrepo. 2014. El uso eficiente de los forrajes tropicales en la alimentación de los bovinos. Rev. Cienc. Anim. 7:111-132.

Argote, G., y M. Halanoca. 2007. Evaluación y selección de gramíneas forrajeras tolerantes a condiciones climáticas del Altiplano de Puno. Sitio Argentino de Producción Animal, ARG. http://www.produccion-animal.com.ar/produccion_y_ manejo_pasturas/pasturas_cultivadas_verdeos_invierno/45-ARGOTE-GramineasForrajeras.pdf (consultado 15 dic. 2018).

Ariza-Nieto, C., O. Mayorga, B. Mojica, D. Parra, and G. Afanador-Tellez. 2017. Use of LOCAL algorithm with near infrared spectroscopy in forage resources for grazing systems in Colombia. J. Near Infrared Spectrosc. 26(1):44-52. doi: $10.1177 / 0967033517746900$

Baizán, S., F. Mainar, M. González, C. González, B. De-la-Roza, A. Soldado, y A. Martínez. 2015. Alternativas forrajeras sostenibles como cultivo invernal en zonas templadas. Pastos 45(2):23-32.

Betancourt, J., H. Cuastumal, S. Rodríguez, J. Navia, y E. Insuasty. 2012. Alimentación de vacas holstein con suplemento de papa de desperdicio (Solanum tuberosum) y acacia negra (Acacia decurrens), y su efecto en la calidad de leche. Rev. Investig. Pecu. 1(2):41-51.

Biondo, P., J. Boeing, E. Barizão, N. de-Souza, M. Matsushita, C. de-Oliveira, M. Boroski, and J. Visentainer. 2014. Evaluation of beetroot (Beta vulgaris L .) leaves during its developmental stages: a chemical composition study. Food Sci. Technol. 34:94-101. doi:10.1590/S0101-20612014005000007

Bolaños, A., B. Arcila, J. Apráez, y O. Moncayo. 2003. Obonuco Avenar. Nueva variedad mejorada de avena forrajera para la alimentación de bovinos de los sistemas de producción del Altiplano de Nariño. Plegable divulgativo No. 11. Corporación Colombiana de Investigación Agropecuaria (CORPOICA), Pasto, COL.

Broderick, G., N. Luchini, S. Reynal, G. Varga, and V. Ishler. 2008. Effect on production of replacing dietary starch with sucrose in lactating dairy cows. J. Dairy Sci. 91:4801-4810. doi:10.3168/jds.2008-1480

Broderick, G., and W. Radloff. 2004. Effect of molasses supplementation on the production of lactating dairy cows fed diets based on alfalfa and corn silage. J. Dairy Sci. 87:2997-3009. doi:10.3168/jds.S0022-0302(04)73431-1

Carulla, J., y E. Ortega. 2016. Sistemas de producción lechera en Colombia: retos y oportunidades. Arch. Latinoam. Prod. Anim. 24(2):83-87.

Castillo, M., A. Rojas, y R. WingChing. 2009. Valor nutricional del ensilaje de maíz cultivado en asocio con Vigna (Vigna radiata). Agron. Costarricense 33(1):133-146.

Chilibroste, P. 2012. Uso de subproductos industriales en la nutrición de bovinos de leche: una oportunidad para la lechería Nacional. En: Centro Médico Veterinario de Paysaindú, editor, XL Jornadas Uruguayas de Buiatría. Centro Médico Veterinario de Paysaindú, URU.p. 34-42. 
Climate-Data.Org. 2018. Clima: Pasto, Cumbal y Sapuyes. Climate-Data.org, Oedheim, DEU. https://es.climate-data.org/ (consultado 15 mar. 2018).

de-la-Roza, B., A. Martínez, y A. Argamentería. 2008. Leguminosas forrajeras anuales para rotación de cultivos en zonas templado - húmedas. Cultivos forraje. Ministerio de Agricultura Pesca y Alimentación, ESP. https://www.mapa.gob.es/ ministerio/pags/Biblioteca/Revistas/pdf_Vrural\%2FVrural_2008_270_16_20.pdf (consultado 3 feb. 2019).

Echeverry, J., L. Restrepo, y J. Parra. 2010. Evaluación comparativa de los parámetros productivos y agronómicos del pasto Kikuyo Pennisetum clandestinum bajo dos metodologías de fertilización. Rev. Lasallista Invest. 7(2):94-100.

Edwards, G., J. Ruiter, D. Dalley, J. Pinxterhuis, and K. Cameron. 2014. Dry matter intake and body condition score change of dairy cows grazing fodder beet, kale and Kale-Oat forage systems in winter. Proc. N. Z. Grassl. Assoc. 76:81-88.

Eraso, M., G. Zambrano, F. Tobar, y H. Ojeda. 2014. Evaluación agronómica del pasto brasilero Phalaris sp., en tres municipios del Departamento de Nariño, empleando fertilización orgánica. Agronomía 22(1):58-65.

Evans, E., and U. Messerschmidt. 2017. Review: Sugar beets as a substitute for grain for lactating dairy cattle. J. Anim. Sci. Biotechnol. 8:25. doi:10.1186/s40104-017-0154-8

Forbes, J. 2007. A personal view of how ruminant animals control their intake and choice of food: minimal total discomfort. Nutr. Res. Rev. 20:132-146. doi:10.1017/S0954422407797834

Fulkerson, W., J. Neal, C. Clark, A. Horadagoda, K. Nandra, and I. Barchia. 2007. Nutritive value of forage species grown in the warm temperate climate of Australia for dairy cows: grasses and legumes. Livest. Sci. 107:253-264. doi:10.1016/j. livsci.2006.09.029

Gallegos, A., A. Martínez, M. Sánchez, R. Figueroa, S. Berumen, J. Venegas, J. Quevedo, D. Escobedo, y M. Silos. 2012. Calidad nutricional de maíz forrajero (Zea mays L.) bajo condiciones limitadas de agua de riego. AGROFAZ 12(1):59-66.

Guerrero R. 1998. Fertilización de cultivos en clima frío. $2^{\text {da }}$ ed. Colombo Venezolanos S.A., Bogotá, COL.

Hoffmann, C., T. Huijbregts, N. van-Swaaij, and R. Jansen. 2009. Impact of different environments in Europe on yield and quality of sugar beet genotypes. Eur. J. Agron. 30:17-26. doi:10.1016/j.eja.2008.06.004

Holdridge, L. 1982. Ecología basada en zonas de vida. IICA, San José, CRI.

Jung, H., and A. Deetz. 1993. Cell wall lignification and degradability. In: H.G. Jung et al., editors, Forage cell wall structure and digestibility. American Society of Agronomy Inc., Crop Science Society of America Inc., and Soil Science Society of America Inc., Madison, WI, USA. p. 315-346. doi:10.2134/1993 foragecellwall.c13

Kafilzadeh, F., and N. Heidary. 2013. Chemical composition, in vitro digestibility and kinetics of fermentation of whole-crop forage from 18 different varieties of oat (Avena sativa L.). J. Appl. Anim. Res. 41:61-68. doi:10.1080/09712119.2012.739084

Lanzas, C., C. Sniffen, S. Seo, L. Tedeschi, and D. Fox. 2007. A revised CNCPS feed carbohydrate fractionation scheme for formulating rations for ruminants. Anim. Feed Sci. Technol. 136:167-190. doi:10.1016/j.anifeedsci.2006.08.025

Lira, S.R. 2007. Fisiología vegetal. 2a ed. Universidad Autónoma Agraria Antonio Navarro, MEX.

Mamani, J. 2016. Avena forrajera: rendimiento, valor nutricional, ventaja comparativa y competitiva en la región Puno. Tesis Ph.D., Universidad Nacional del Altiplano, Puno, PER.

Martínez, A., B. de-la-Roza, A. Soldado, y A. Argamentería. 2005a. Evaluación de producción y valor nutritivo de Las habas forrajeras como alternativa al raigrás Italiano utilizadas como cultivo de invierno en rotación con el maíz. En: B. dela-Roza et al., editores, Actas de la XLV Reunión Científica de la Sociedad Española para el Estudio de los Pastos, Producciones agroganaderas: gestión eficiente y conservación del medio natural. Vol. 2. Sociedad Española para el Estudio de los Pastos, Asturias, ESP. p. 681-688. 
Martínez, A., N. Pedrol, y J. Piñero. 2005b. Cultivares de haboncillo (Vicia faba L.) y triticale (x Triticosecale Wittm.) para producción de forraje invernal en zonas húmedas con mezclas cereal - leguminosa. En: B. de-la-Roza et al., editores, Actas de la XLV Reunión Científica de la Sociedad Española para el Estudio de los Pastos, Producciones agroganaderas: gestión eficiente y conservación del medio natural. Vol. 2. Sociedad Española para el Estudio de los Pastos, Asturias, ESP. p. 673-679.

Martínez, A., F. Vicente, S. Baizán, y N. Barhoumi. 2017. Interés agronómico de la inclusión de las habas forrajeras en la raciones de rumiantes en la cornisa cantábrica. Afriga 131:88-96.

Mejía, S., H. Cuadrado, y T. Rivero. 2013. Manejo agronómico de algunos cultivos forrajeros y técnicas para su conservación en la región caribe Colombiana. 2a ed. Corporación Colombiana de Investigaciópn Agropecuaria (CORPOICA), Bogotá, COL.

Molano R., F. Aguilar, J. Carulla, y G. Afanador. 2011. Sistemas integrados de alimentación en bovinos. Universidad Nacional de Colombia, Bogotá, COL.

Mora, J., J. Romero, y L. Zamora. 2014. Viabilidad financiera de modelos de manejo de rumiantes en sistemas silvopastoriles con y sin suplementación estratégica. Agrofor. Neotrop. 4:52-60.

Morales, A., J. León, E. Cárdenas, G. Afanador, y J. Carulla. 2013. Composición química de la leche, digestibilidad in vitro de la materia seca y producción en vacas alimentadas con grampíneas solas o asociadas con Lotus uliginosus. Rev. Med. Vet. Zoot. 60(1):32-48.

Moreno, A., J. Cantú, J. Reyes, and V. Contreras. 2017. Forage maize nutritional quality according to organic and inorganic fertilization. Sci. Agropecu. 8:127-135. doi:10.17268/sci.agropecu.2017.02.05

Navia, J., D. Muñoz, y J. Solarte. 2015. Caracterización biofísica y socioeconómica de fincas ganaderas de leche en el Municipio de Guachucal, Nariño. Rev. Temas Agrar. 20:113-129. doi:10.21897/rta.v20i1.753

Núñez, G., F. González, J. Bonilla, y J. Bustamante. 2009. Alimentación del ganado lechero. Capitulo 3. En: G. Núñez et al., editores, Producción de leche de bovino en el sistema intensivo. Libro técnico 23. Instituto Nacional de Investigaciones Forestales, Agrícolas y Pecuarias (INIFAP), Veracruz, MEX. p. 81-116.

Núñez, G., J. Payán, O. Ruiz, y C. Arzola. 2006. Calidad nutricional del forraje y producción de leche del ganado bovino. Capítulo VI. En: G. Nuñez, editor, Maíz forrajero de alto rendimiento y calidad nutricional. Libro científico 3 . Instituto Nacional de Investigaciones Forestales, Agrícolas y Pecuarias (INIFAP), México D.F., MEX. p. 217-238.

Oba, M. 2011. Review: Effects of feeding sugars on productivity of lactating dairy cows. Can. J. Anim. Sci. 91(1):37-46. doi:10.4141/CJAS10069

Osmane, B., I. Konosonoka, A. Trupa, and L. Proskina. 2017. Peas and beans as a protein feed for dairy cows. Agron. Res. 15:2026-2038. doi:10.15159/ar.17.027

Provenza, F. 1995. Postingestive feedback as an elementary determinant of food preference and intake in ruminants. J. Range Manag. 48(1):2-17. doi:10.2307/4002498

Ramos, R., M. Pabón, y J. Carulla. 1998. Factores nutricionales y no nutricionales que determinan la composición de la leche. Rev. Med. Vet. Zoot. 46(2):2-7.

Reta, D., U. Figueroa, R. Faz, G. Núñez, A. Gaytán, J. Serrato, y J. Payán. 2010. Sistemas de producción de forraje para incrementar la productividad del agua. Rev. Fitotec. Mex. 33(4):83-87.

Reta, D., J. Serrato, R. Figueroa, J. Cueto, S. Berúmen, y J. Santamaría. 2008. Cultivos alternativos con potencial de uso forrajero en la comarca lagunera. 3a ed. Instituto Nacional de Investigaciones Forestales, Agrícolas y Pecuarias (INIFAP), Ciudad de México, MEX. 
Ruiz, O., R. Beltrán, F. Salvador, H. Rubio, A. Grado, y Y. Castillo. 2006. Valor nutritivo y rendimiento forrajero de híbridos de maíz para ensilaje. Rev. Cuba. Cienc. Agric. 40(1):91-96.

Salas, A., y J. Córdoba. 2013. Evaluación de dos sistemas de reproducción vegetativa y tres distancias de siembra para la producción del pasto brasilero (Phalaris Sp.) en la Granja Chimangual de la Universidad de Nariño. Tesis Lic., Universidad de Nariño, Nariño, COL.

Salinas, J. 1982. Muestreo de suelo y tejido vegetal en los ensayos regionales A y B. En: J.M. Toledo, editor, Manual para la evaluación agronómica. Red Internacional de Evaluación de Pastos Tropicales. CIAT, Cali, COL. p. 111-116.

Salmerón, J.J., F.J. Meda, y J.R. Barcena. 2003. Variedades de avena y calidad nutricional del forraje. Folleto técnico 17. Instituto Nacional de Investigaciones Forestales, Agrícolas y Pecuarias (INIFAP), Cuauhtémoc, MEX.

Schwab, E., R. Shaver, J. Lauer, and J. Coors. 2003. Estimating silage energy value and milk yield to rank corn hybrids. Anim. Feed Sci. Technol. 109:1-18. doi:10.1016/S0377-8401(03)00210-4

Silva, A., M. Blanca, O. Toapanta, y S. Dora. 2011. Elaboración de vino de remolacha a partir de dos variedades (Beta vulgaris), conditiva y macrohiza, utilizando dos endulzantes naturales stevia (Stevia rebaudiana) y miel de abeja. Tesis pregrado. Universidad Técnica de Cotopaxi, Latacunga, ECU.

Trujillo, G. 2009. Guía para la utilización de recursos forrajeros tropicales para la alimentación de bovinos. Convenio 0367/09. Comité de Ganaderos del Huila, SENA, Fondo Granadero del Huila, y Gobernación del Huila, Huila, COL.

Ulrich, A. 2018. Composição bromatológica, degradabilidade e produção de gases “in vitro" de aveia, azevém e nabo-forrageiro. Tesis Bach., Universidade Federal da Fronteira Sul, Santa Catarina, BRA.

UDENAR (Universidad de Nariño). 2016. Granja lechera Chimangual. Universidad de Nariño, COL. www.udenar.edu.co/ project/granja-lechera-chimangual/ (consultado 06 nov. 2018).

Zamora, V., M. Colín, M. Torres, A. Rodríguez, y M. Jaramillo. 2016. Producción y valor nutritivo en fracciones de forraje de trigos imberbes. Rev. Mex. Cien. Agríc. 7:291-300. 